\title{
PENANGANAN TERHADAP FINANCIAL TECHNOLOGY PEER-TO-PEER LENDING ILEGAL MELALUI OTORITAS JASA KEUANGAN (Studi Pada OJK Jakarta Pusat)
}

\author{
Alifia Salvasani \\ E-mail: avasalva@gmail.com \\ Mahasiswa Fakultas Hukum Universitas Sebelas Maret Surakarta \\ Munawar Kholil \\ E-mail: munawar.kholil@gmail.com \\ Dosen Fakultas Hukum Universitas Sebelas Maret Surakarta
}

\begin{abstract}
This article aims to examine the role of Otoritas Jasa Keuangan (OJK) in handling illegal peer-to-peer (P2P) financial technology (fintech) in Indonesia. This role includes the handling carried out by the FSA to minimize the number of illegal fintech in Indonesia, both through supervision and arrangements related to illegal fintech. This type of empirical legal research, is descriptive, with primary data types. Literature study and interview data collection techniques, qualitative analysis techniques. Factors causing the rise of illegal fintech are normative and non-normative factors. Then the role of the OJK in making efforts to handle illegal P2P lending includes establishing Satgas Waspada Investasi, listing registered $P 2 P$ lending and licensed on the official OJK website, socializing to the public about the characteristics of illegal P2P lending that must be avoided and data of illegal P2P lending in Indonesia, closing illegal $P 2 P$ lending, blocking applications and illegal $P 2 P$ lending websites on a regular basis, conducting selective checks on $P 2 P$ lending companies that propose opening new accounts, applying special rules for $P 2 P$ lending companies related to the fintech payment system, and submit information reports to the Criminal Investigation Police regarding cyber crime.
\end{abstract}

Keywords: Otoritas Jasa Keuangan; Illegal Fintech; Peer-to-Peer

\begin{abstract}
Abstrak
Artikel ini bertujuan untuk mengkaji peranan Otoritas Jasa Keuangan (OJK) dalam menangani financial technology (fintech) peer-to-peer (P2P) lending ilegal di Indonesia. Peranan tersebut meliputi penanganan yang dilakukan OJK untuk meminimalisir jumlah fintech ilegal di Indonesia, baik melalui pengawasan maupun pengaturan terkait fintech ilegal. Jenis penelitian hukum empiris, bersifat deskriptif, dengan jenis data primer. Teknik pengumpulan data studi kepustakaan dan wawancara, teknik analisis kualitatif. Faktor penyebab tumbuh maraknya fintech ilegal adalah adanya faktor normatif dan non-normatif. Kemudian peranan OJK dalam melakukan upaya penanganan P2P lending ilegal antara lain dengan membentuk Satgas Waspada Investasi, mencantumkan daftar P2P lending yang terdaftar dan berizin di website resmi OJK, mensosialisasikan kepada masyarakat terkait ciri-ciri P2P lending ilegal yang harus dihindari dan data P2P lending ilegal di Indonesia, melakukan penutupan terhadap P2P lending ilegal, pemblokiran aplikasi dan website P2P lending ilegal secara rutin, melakukan pemeriksaan secara selektif bagi perusahaan $\mathrm{P} 2 \mathrm{P}$ lending yang mengajukan pembukaan rekening baru, memberlakukan aturan khusus bagi perusahaan P2P lending terkait fintech payment system, dan menyampaikan laporan informasi kepada Bareskrim Polri terkait tindakan cyber crime.
\end{abstract}

Kata Kunci: Otoritas Jasa Keuangan; Fintech llegal; Peer-to-Peer Lending

\section{A. Pendahuluan}

Perkembangan pada bidang teknologi dan informasi di era globalisasi saat ini merupakan suatu fenomena yang mempermudah manusia di segala sektor kehidupan. Di Indonesia, kemajuan tersebut berdampak pada pergerakan start-up yang terus mengalami perkembangan 
Jenis start-up dibedakan menjadi dua, yaitu e-commerce dan Financial Technology (Fintech). (Ana Sofa Yuking, 2018: 1). E-commerce merupakan sistem pemasaran barang dan jasa yang mengandalkan sistem elektronik yang berupa transfer dana dan pertukaran data elektronik, sistem manajemen, dan pengumpulan data secara otomatis. Sedangkan yang dimaksud dengan fintech yaitu inovasi pada bidang keuangan yang menggunakan teknologi modern, sehingga transaksi keuangan menjadi lebih praktis, aman, dan modern.

Fintech hadir dengan menawarkan berbagai kemudahan dalam bidang keuangan, yaitu untuk mencapai kecepatan, keefektifan, dan keefisienan akses terhadap aktivitas perbankan seperti transaksi, menabung dan lain lain yang dapat dilakukan melalui ATM, e-money dan Telkomsel cash yang selama ini telah menjadi salah satu dari beberapa program yang telah dilakukan Bank Indoensia untuk terobosan baru teknologi keuangan. (Fitri Rusdianasari, 2018: 253).

Pelaksanaan fintech di Indonesia berada di bawah kewenangan Otoritas Jasa Keuangan (OJK). Dalam hal ini, OJK merupakan lembaga independen yang memegang otoritas tertinggi, sehingga mendapat pemindahan fungsi pengaturan dan pengawasan pada seluruh lembagalembaga keuangan dan bisnis keuangan di Indonesia. Seluruh lembaga-lembaga keuangan dan bisnis keuangan tersebut berada di bawah pengaturan dan pengawasan OJK yang bebas dari intervensi pihak manapun. (Andrian Sutedi, 2014: 78). Oleh karena itu, hal-hal yang berkaitan dengan fintech diatur pada Peraturan Otoritas Jasa Keuangan (POJK) Nomor 77/POJK.01/2016. Diberlakukannya peraturan tersebut bertujuan untuk menjaga para pihak di dalamnya, yaitu konsumen dan institusi keuangan. Dalam peraturan tersebut, OJK mengatur mengenai peer to peer lending (P2P lending), yaitu bisnis pinjaman dari pengguna ke pengguna. P2P lending adalah jenis fintech yang paling banyak diminati oleh masyarakat di Indonesia. P2P lending menyediakan platform pinjaman online dan dapat digunakan untuk modal dalam membuka usaha.

Berkaitan dengan perlindungan konsumen, hal tersebut diatur dalam UndangUndang Nomor 11 Tahun 2008 tentang Informasi dan Transaksi Elektronik (UU ITE). Di dalam UU ITE terdapat aturan terkait perlindungan data pribadi, yang mana harus ada persetujuan atas orang yang bersangkutan terkait penggunaan setiap informasi melalui media elektronik yang menyangkut data pribadi orang tersebut.

Perusahaan fintech di Indonesia masih terus berkembang, bahkan di Indonesia pertumbuhannya sangat tinggi setiap tahunnya. Fenomena ini dianggap sangat penting karena di masa depan, sektor teknologi keuangan diharapkan dapat bertindak sebagai pendorong utama pertumbuhan ekonomi di Indonesia. (Ichwan dan Rahmatina A. Kasri, 2019: 743). Namun di sisi lain, banyak ditemukan permasalahan pada penerapan fintech di Indonesia. Salah satu permasalahan tersebut yaitu ditemukannya fintech berbentuk P2P lending ilegal atau tidak sah menurut hukum. Pertumbuhan P2P lending di Indonesia pun akhirnya tidak hanya pada P2P lending yang legal saja, namun P2P lending ilegal juga. Dalam hal ini P2P lending ilegal banyak diminati oleh masyarakat karena adanya kemudahan prosedur dalam pinjaman online. Adanya kemudahan prosedur dalam pinjam meminjam online tersebut justru membuat timbulnya risiko gagal bayar bagi peminjam maupun pemberi pinjaman. Risiko ini nantinya harus ditebus dengan rata-rata bunga pinjaman di atas bunga kredit perbankan konvensional pada umumnya, atau terbilang cukup mahal yaitu rata-rata di atas $19 \%$.

Permasalahan di atas adalah salah satu bentuk kendala dalam pertumbuhan fintech P2P lending di Indonesia. Dalam hal ini, masyarakat tentu saja merasa dirugikan atas kehadiran P2P lending ilegal. Terkait permasalahan P2P lending ilegal tersebut, OJK dianggap masih belum mampu menangani banyaknya kasus P2P lending ilegal yang meresahkan masyarakat. Problem inilah yang akan dikaji dalam artikel ini.

\section{B. Metode Penelitian}

Penelitian ini merupakan jenis penelitian hukum empiris yang bersifat deskriptif dengan pendekatan yuridis empiris. Jenis dan sumber data yang digunakan adalah bahan hukum primer 
yang diperoleh dari Kitab Undang-Undang Hukum Perdata, Undang - Undang Nomor 21 Tahun 2011 tentang Otoritas Jasa Keuangan, dan peraturan perundang-undangan lain yang berkaitan dengan penelitian penulis. Bahan hukum sekunder yang diperoleh dari buku-buku teks hukum yang ditulis oleh para ahli hukum, jurnal hukum, artikel hukum, literatur yang terkait, karya ilmiah, dan hasil penelitian lainnya. Teknik pengumpulan data yang digunakan adalah studi kepustakaan atau studi dokumen, dengan teknik pengolahan data menggunakan metode yuridis kualitatif, yaitu mengungkapkan dan memahami kebenaran masalah serta pembahasan dengan menafsirkan data yang diperoleh kemudian menuangkannya dalam bentuk kalimat yang tersusun secara terinci dan sistematis.

\section{Hasil Penelitian dan Pembahasan}

Financial technology (fintech) adalah sebuah inovasi baru dalam jasa finansial yang mengubah model bisnis menjadi lebih modern dengan memanfaatkan teknologi. Fintech merupakan suatu industri yang bergerak sangat cepat dan dinamis. Fintech dibagi menjadi beberapa jenis, berdasarkan bentuk atau jenis inovasi, salah satunya yaitu peer to peer lending (P2P lending). Di Indonesia, P2P lending merupakan salah satu jenis fintech yang paling banyak diminati oleh masyarakat. P2P lending biasa dikenal sebagai layanan pinjam meminjam uang berbasis teknologi. P2P lending merupakan penyelenggaraan layanan jasa keuangan untuk mempertemukan pemberi pinjaman dengan penerima pinjaman dalam rangka melakukan perjanjian pinjam meminjam melalui internet. P2P lending dapat didefinisikan sebagai "perubahan finansial" yang terjadi langsung antara individu tanpa intermediasi lembaga keuangan tradisional. Bank masih berperan sesuai dengan peraturan, yaitu bertindak sebagai lembaga penyimpanan, yang digunakan untuk menyediakan platform dengan akun di mana uang disimpan, dan menaruhnya di platform. (Eugenia Omarini A, 2018: 31). Teknis penyelenggaraan dalam P2P lending yaitu penyelenggara sebagai pihak ketiga akan mempertemukan debitur dan kreditur melalui sebuah platform yang dikelolanya. Penyelenggara dapat menjadi pihak yang menyeleksi dan menyetujui pengajuan pinjaman debitur.

Pada dasarnya, pelaksanaan fintech di Indonesia berada di bawah kewenangan Otoritas Jasa Keuangan (OJK). Hal tersebut dikarenakan OJK merupakan lembaga independen yang memegang otoritas tertinggi, sehingga mendapat pemindahan fungsi pengaturan dan pengawasan pada seluruh lembaga-lembaga keuangan dan bisnis keuangan di Indonesia. Dalam melakukan pengawasan terkait fintech di Indonesia, OJK telah mengeluarkan aturan mengenai fintech peer to peer lending melalui POJK Nomor 77/POJK.01/2016 tentang Layanan Pinjam Meminjam Uang Berbasis Teknologi Informasi. Adanya aturan tersebut menjadi dasar dalam pelaksanaan fintech dan diharapkan dapat meminimalisir permasalahan terkait fintech di Indonesia. Berkaitan dengan pertumbuhan fintech ilegal di Indonesia, sebenarnya di dalam POJK Nomor 77/ POJK.01/2016 tersebut sudah dicantumkan cara untuk melakukan pengajuan pendaftaran suatu perusahaan fintech yang mana harus sesuai dengan syarat yang dijelaskan di dalam POJK. Suatu perusahaan dapat mendaftar ke OJK dengan mengajukan permohonan yang dilengkapi persyaratan sebagaimana dicantumkan dalam POJK.

Beberapa tahun belakangan sejak pertumbuhan fintech P2P lending ilegal semakin tinggi, OJK semakin memperketat pendaftaran fintech dengan melakukan pencatatan dan pengawasan. Disamping itu, OJK juga melakukan pembaharuan regulasi yang dikeluarkan khusus untuk mengatur fintech, dengan dikeluarkan aturan baru yaitu POJK Nomor 13/POJK.02/2018 tentang Inovasi Keuangan Digital (IKD) di Sektor Jasa Keuangan. Aturan ini merupakan ketentuan yang memayungi pengawasan dan pengaturan industri fintech. Munculnya POJK Nomor 13/ POJK.02/2018 tentang IKD tersebut memiliki fungsi sebagai wadah pertama bagi fintech jenis baru. Dalam hal ini OJK akan mengawasi pelaku fintech yang belum diakomodasi oleh kerangka hukum manapun (regulatory sandbox). Apabila sudah ada peraturan yang mengatur dan lebih spesifik, maka pelaku fintech tersebut akan keluar dari regulatory sandbox dan harus tunduk pada 
kerangka hukum yang lebih spesifik. Sebenarnya kedua peraturan tersebut saling berkaitan, yang mana POJK Nomor 77/POJK.01/2016 merupakan dasar hukum bagi fintech jenis P2P lending. Karena hadirnya POJK Nomor 77/POJK.01/2016 yang lebih awal sebelum POJK Nomor 13/ POJK.02/2018, membuat pelaku fintech P2PL tidak mendapat kesempatan untuk mengikuti regulatory sandbox dan langsung wajib tunduk kepada POJK Nomor 77/POJK.01/2016. Adanya aturan POJK Nomor 77/POJK.01/2016 tersebut sebenarnya sudah merujuk pada fintech $\mathrm{P} 2 \mathrm{P}$ lending, namun aturan tersebut hanya berlaku bagi fintech $\mathrm{P} 2 \mathrm{P}$ lending yang legal saja.

Di Indonesia, fintech telah berkembang sejak tahun 2006. Namun P2P lending itu sendiri baru muncul pertama kali pada tahun 2016 dan terus mengalami pertumbuhan. Data di website resmi OJK per 9 Desember 2017, disebutkan bahwa terdapat 11 perusahaan peminjaman kredit fintech yang terdaftar. Kemudian per 27 Januari 2018, jumlah perusahaan pinjaman kredit fintech terdaftar di Indonesia Indonesia mencapai 32 perusahaan, dan 17 di antaranya adalah pinjaman peer to peer. Pada tahun 2019, dalam website resmi OJK terdapat 25 perusahaan fintech terdaftar dan berizin OJK.

Sebenarnya terdapat beberapa faktor yang mendorong tumbuh maraknya fintech ilegal berbentuk P2P lending di Indonesia, yang kemudian dapat dikategorikan menjadi dua faktor:

1. Faktor Normatif

a. Tidak adanya aturan terkait besaran suku bunga P2P lending.

Saat ini aturan penetapan besaran suku bunga P2P lending hanya disesuaikan dengan profil dan skala usahanya. Aturan tersebut diatur secara tidak langsung melalui Asosiasi Fintech Pendanaan Bersama Indonesia (AFPI).

b. Kurang maksimalnya penegakan hukum P2P lending ilegal.

Sampai saat ini OJK baru memberlakukan sanksi bagi fintech P2P lending yang terdaftar dan berizin saja. Sedangkan terkait banyaknya aplikasi fintech ilegal, OJK hanya dapat melakukan upaya penutupan dan pemblokiran aplikasi melalui SWI yang kemudian ditindaklanjuti oleh Kemkominfo.

c. Belum adanya ketentuan pidana yang menjerat P2P lending tanpa izin, karena pengaturannya hanya sebatas Peraturan OJK (POJK) atau setingkat.

Saat ini OJK melalui POJK Nomor 77/POJK.01/2016 hanya mengatur sanksi bagi fintech P2P lending yang terdaftar dan berizin OJK saja. Sedangkan terkait pelanggaran yang lebih jauh, OJK akan menyampaikan laporan kepada Bareskrim Polri untuk proses penegakan hukum.

2. Faktor Non-Normatif

a. Pengawasan P2P lending ilegal yang sulit dilakukan

Pengawasan terkait P2P lending ilegal sulit dilakukan karena perkembangannya yang sangat pesat padahal SWI membutuhkan waktu yang lama untuk mendeteksi aplikasi P2P lending ilegal.

b. Pengetahuan atau literasi masyarakat yang minim terkait P2P lending

Masyarakat masih asal dalam memilih website pinjaman online dan tidak mengetahui dampak yang ditimbulkan apabila mereka melakukan pinjaman online di P2P lending ilegal, misalnya tingginya suku bunga pinjaman yang akan memberatkan masyarakat.

c. Permintaan P2P lending ilegal yang tinggi dari masyarakat

Banyak masyarakat yang lebih memilih melakukan pinjaman online melalui platform $\mathrm{P} 2 \mathrm{P}$ lending ilegal karena kemudahan dalam prosedur pinjaman jika dibandingkan dengan P2P lending legal atau perbankan. 
d. Kemudahan dalam proses pembuatan aplikasi atau website

Adanya kemajuan teknologi ditambah dengan proses pembuatan aplikasi atau website yang mudah memungkinkan semua orang untuk membuat P2P lending ilegal. Disamping itu, adanya kemajuan teknologi memungkinkan adanya keberadaan lintas negara. Fenomena tersebut menyebabkan banyaknya server fintech P2P lending ilegal yang keberadaannya di luar negeri.

Pada dasarnya, OJK tidak memiliki kewenangan khusus dalam penanganan fintech P2P lending ilegal. Karena adanya keterbatasan tersebut, kemudian dibentuklah Satgas Waspada Investasi (SWI) yang berada di bawah pengawasan OJK. SWI dibentuk untuk mencegah dan menangani dugaan tindakan melawan hukum di bidang penghimpunan dana dan pengelolaan investasi, termasuk penghimpunan dana dan pengelolaan investasi yang dilakukan melalui platform fintech. SWI merupakan forum koordinasi untuk menangani kasus-kasus penipuan berkedok penawaran investasi atau penawaran investasi tanpa izin (ilegal) termasuk fitech ilegal. SWI merupakan hasil kerja sama beberapa instansi pemerintah, dengan harapan agar upaya OJK untuk meminimalisir perkembangan P2P lending ilegal dapat dioptimalkan dengan kerjasama antara para instansi tersebut, sebab ada beberapa tugas dari Satgas yang pelaksanaannya bukan merupakan kewenangan OJK.

Namun karena adanya keterbatasan dari pihak OJK terkait penanganan P2P lending ilegal, maka permasalahan tersebut belum dapat ditangani secara maksimal. Hal tersebut dikarenakan fintech P2P lending ilegal bukan merupakan ranah kewenangan OJK. Karena adanya keterbatasan tersebut, OJK melalui SWI hanya dapat meng-cover permasalahan yang berkaitan dengan fintech P2P lending ilegal melalui kerjasama dengan beberapa instansi antara lain Kemkominfo dan Bareskrim Polri.

Saat ini OJK masih terus melakukan upaya terkait penanganan terhadap P2P lending ilegal di Indonesia. Upaya tersebut dilakukan oleh OJK sebagai cara untuk meminimalisir pertumbuhan P2P lending ilegal di Indonesia. Berikut peranan OJK dalam melakukan upaya penanganan $\mathrm{P} 2 \mathrm{P}$ lending ilegal:

1. Mencantumkan daftar P2P lending yang terdaftar dan berizin di website resmi OJK.

Hal tersebut dilakukan dengan tujuan agar masyarakat mengetahui dan menggunakan fintech legal sesuai data dalam website resmi OJK.

2. Mensosialisasikan kepada masyarakat terkait ciri-ciri P2P lending ilegal yang harus dihindari.

Beberapa website yang berada di bawah pengawasan OJK (www.duwitmu.com) selalu update terkait permasalahan dan ciri-ciri P2P lending ilegal.

3. Memberitahukan kepada masyarakat mengenai data dan informasi P2P lending ilegal di Indonesia.

Pihak OJK selalu memberitahukan data terbaru terkait P2P lending ilegal tersebut melalui keterangan resmi yang kemudian dapat dibaca pada website seperti CNN, Kompas, Detik, dan lain sebagainya.

4. Melakukan penutupan terhadap P2P lending illegal.

Penutupan fintech P2P lending ilegal tersebut dilakukan oleh SWI dengan cara menghentikan izin pengoperasian perusahaan fintech P2P lending ilegal di Indonesia.

5. Pemblokiran aplikasi dan website $\mathrm{P} 2 \mathrm{P}$ lending ilegal secara rutin.

Pemblokiran aplikasi dan website tersebut dilakukan melalui permohonan atau pengajuan oleh SWI kepada Kemkominfo.

6. Melakukan pemeriksaan secara selektif bagi perusahaan P2P lending yang mengajukan pembukaan rekening baru SWI meminta agar pihak perbankan menghambat perkembangan fintech P2P lending ilegal sejak awal pendaftaran rekening baru. 
7. Memberlakukan aturan khusus bagi perusahaan P2P lending terkait fintech payment system.

Sesuai dengan POJK Nomor 77/POJK.01/2016, penyelenggara fintech P2P lending wajib membuka virtual account di Bank yang berkedudukan di Indonesia serta telah memiliki izin usaha sebagai Bank.

8. Menyampaikan laporan informasi kepada Bareskrim Polri terkait tindakan cybercrime.

SWI akan menyampaikan laporan informasi kepada Bareskrim Polri apabila para pelaku P2P lending ilegal melakukan penagihan disertai teror, intimidasi, atau pencemaran nama baik.

Disamping banyaknya upaya yang telah dilakukan oleh OJK, namun upaya tersebut masih dianggap belum maksimal. Hal tersebut dapat dilihat dari masih banyaknya laporan terkait permasalahan yang ditimbulkan oleh P2P lending ilegal. Dapat diketahui bahwa laporan fintech P2P lending ilegal yang diterima OJK akhir-akhir ini meningkat jumlahnya. Beberapa laporan yang diterima OJK terkait fintech P2P lending ilegal antara lain yaitu:

1. Bunga pinjaman tinggi

2. Aplikasi fintech ilegal yang berganti nama dan bunga pinjaman terus bertambah

3. Penagihan dilakukan dengan cara pengancaman sampai pencemaran nama baik

4. Penagihan dilakukan kepada kontak darurat yang dicantumkan oleh peminjam

5. Tidak hapusnya pinjaman padahal peminjam sudah membayarnya

6. Penyebaran data pribadi peminjam oleh perusahaan fintech ilegal

7. Penggunaan data KTP peminjam oleh perusahaan aplikasi fintech ilegal untuk mengajukan pinjaman di aplikasi lain

(Hasil wawancara dengan Andrei Romario selaku staf di Bagian Deputi Direktur Kebijakan Penyidikan OJK pada tanggal 3 Februari 2020).

Namun karena adanya keterbatasan dari pihak OJK terkait penanganan P2P lending ilegal, maka permasalahan tersebut belum dapat ditangani secara maksimal. Dalam hal ini, OJK tidak memiliki kewenangan yang berkaitan dengan tindak pencemaran nama baik atau bahkan kekerasan dalam penagihan yang dilakukan oleh P2P lending ilegal. Hal tersebut dikarenakan fintech P2P lending ilegal bukan merupakan ranah kewenangan OJK. Apabila terjadi pelanggaran yang dilakukan fintech $\mathrm{P} 2 \mathrm{P}$ lending yang terdaftar dan berizin, SWI dapat melakukan penindakan terhadap fintech tersebut. Kemudian pihak OJK menegaskan, apabila ada laporan atau aduan yang masuk terkait tindak kekerasan dan pelecehan yang dilakukan saat penagihan atau masuk ke ranah kejahatan cyber maka hal tersebut harus ditindaklanjuti di bawah Kepolisian Republik Indonesia.

Keterbatasan kewenangan yang dimiliki oleh OJK terkait fintech P2P lending ilegal tersebut dilatarbelakangi oleh alasan bahwa selama ini industri fintech hanya diatur dalam POJK Nomor 77/POJK.01/2016. Padahal aturan tersebut dianggap belum jelas, karena tidak memuat penjelasan secara rinci terkait bagaimana kedudukan fintech di mata hukum. Dalam hal ini, adanya aturan yang diterapkan oleh OJK melalui POJK Nomor 77/POJK.01/2016 dianggap belum cukup, khususnya dalam penindakan terhadap P2P lending ilegal yang kerap menetapkan bunga dengan nilai yang tinggi serta melakukan penagihan yang tidak etis kepada peminjam. Sampai saat ini OJK hanya dapat meng-cover permasalahan yang berkaitan dengan fintech $\mathrm{P} 2 \mathrm{P}$ lending ilegal melalui kerjasama dengan beberapa pihak. 


\section{Simpulan}

1. Tumbuhnya fintech peer to peer lending ilegal di Indonesia disebabkan oleh beberapa faktor yang kemudian dikelompokkan menjadi dua kategori, yakni:

a. Faktor normatif:

1) Tidak adanya aturan terkait besaran suku bunga $P 2 P$ lending

2) Kurang maksimalnya penegakan hukum $P 2 P$ lending ilegal

3) Belum adanya ketentuan pidana yang menjerat P2P lending tanpa izin, karena pengaturannya hanya sebatas Peraturan OJK (POJK) atau setingkat

b. Faktor non-normatif:

1) Pengawasan $P 2 P$ lending ilegal yang sulit dilakukan

2) Pengetahuan atau literasi masyarakat yang minim terkait $P 2 P$ lending

3) Permintaan $\mathrm{P} 2 \mathrm{P}$ lending ilegal yang tinggi dari masyarakat

4) Kemudahan dalam proses pembuatan aplikasi atau website

2. Peranan OJK dalam melakukan upaya penanganan P2P lending ilegal antara lain dengan membentuk Satgas Waspada Investasi, mencantumkan daftar P2P lending yang terdaftar dan berizin di website resmi OJK, mensosialisasikan kepada masyarakat terkait ciri-ciri P2P lending ilegal yang harus dihindari, memberitahukan kepada masyarakat mengenai data dan informasi P2P lending ilegal di Indonesia, melakukan penutupan terhadap P2P lending ilegal, pemblokiran aplikasi dan website $\mathrm{P} 2 \mathrm{P}$ lending ilegal secara rutin, melakukan pemeriksaan secara selektif bagi perusahaan P2P lending yang mengajukan pembukaan rekening baru, memberlakukan aturan khusus bagi perusahaan P2P lending terkait fintech payment system, dan menyampaikan laporan informasi kepada Bareskrim Polri terkait tindakan cyber crime.

\section{E. Saran}

Berdasarkan uraian kesimpulan di atas, penulis dapat menyampaikan beberapa saran, antara lain:

1. Pemerintah yakni Presiden bersama DPR perlu menerbitkan regulasi atau UndangUndang khusus yang memberikan kewenangan bagi OJK untuk menindaklanjuti P2P lending ilegal. Selanjutnya Pemerintah perlu melakukan sosialisasi kepada masyarakat terkait P2P lending ilegal melalui social media di bawah pengawasan OJK.

2. OJK perlu membuat sistem pendeteksi dan pemberantas fintech P2P lending ilegal dengan melibatkan pihak lain di luar instansi dan meningkatkan kapasitas Satgas Waspada Investasi.

3. Masyarakat perlu meningkatkan literasi terkait P2P lending serta bahaya yang ditimbulkan dari transaksi pinjaman online di P2P lending ilegal dan lebih hati-hati dalam memilih platform pinjaman onlne.

\section{F. Daftar Pustaka}

\section{Buku}

Adrian Sutedi. 2014. Aspek Hukum Otoritas Jasa Keuangan. Jakarta: Raih Asa Sukses.

\section{Jurnal}

Ana Sofa Yuking. 2018. "Urgensi Peraturan Perlindungan Data Pribadi dalam Era Bisnis Fintech". Jurnal Hukum dan Pasar Modal. Vol. 8, No. 16. Jakarta: Himpunan Konsultan Hukum Pasar Modal.

Arner, Douglas W., Barberis, Janos N., \& Buckley, Ross P. 2017. "Fintech, RegTech and the Reconceptualizing of Financial Regulation". Northwestern Journal of International Law and Business. Vol. 37, Issue 3. Chicago: Northwestern University School of Law. 
Ernama, Budiharto, Hendro S. 2017. "Pengawasan Otoritas Jasa Keuangan terhadap Financial Technology (Peraturan Otoritas Jasa Keuangan Nomor 77/POJK.01/ 2016)". Diponegoro Law Journal. Vol. 6, No.3. Semarang: Fakultas Hukum Universitas Diponegoro.

Eugenia Omarini A. 2018. "Peer-to-Peer Lending: Business Model Analysis and the Platform Dilemma". International Journal of Finance, Economics and Trade (IJFET). Vol. 2, Issue 3. Lewes: SciDoc Publisher.

Fitri Rusdianasari. 2018. "Peran Inklusi Keuangan melalui Integrasi Fintech dalam Stabilitas Sistem Keuangan Indonesia". Jurnal Ekonomi Kuantitatif Terapan (JEKT). Vol. 11, No. 2. Denpasar: Fakultas Ekonomi dan Bisnis Universitas Udayana.

Hesty D. Lestari. 2012. "Otoritas Jasa Keuangan: Sistem Baru dalam Pengaturan dan Pengawasan Sektor Jasa Keuangan”. Jurnal Dinamika Hukum. Vol. 12, No. 3. Purwokerto: Fakultas Hukum Universitas Jenderal Soedirman.

Ichwan dan Rahmatina A. Kasri. 2019. "Why Are Youth Intent on Investing Through Peer to Peer Lending? Evidence from Indonesia". Journal of Islamic Monetary Economics and Finance (JIMF). Vol. 5, No.4. Jakarta: Bank Indonesia.

Raden Ani Eko Wahyuni dan Bambang Eko Turisno. 2019. "Praktik Finansial Teknologi llegal Ditinjau dari Prespektif Etika Bisnis". Jurnal Pembangunan Hukum Indonesia. Vol. 1, No. 3. Semarang: Program Studi Magister IImu Hukum Fakultas Hukum Universitas Diponegoro.

Rinitami Njatrijani. 2019. "Perkembangan Regulasi dan Pengawasan Financial Technology di Indonesia". Diponegoro Private Law Review. Vol. 4, No. 1. Semarang: Hukum Keperdatan Fakultas Hukum Universitas Diponegoro.

Yesaya Eglesias Paulus. 2018. "The Emergence of Peer-to-Peer Lending in Indonesia: A Study of Risk Management Analysis on Conventional Banking Companies". International Journal of Management and Applied Science (IJMAS). Vol. 4, Issue 7. Bhubaneswar: Institute of Research and Journals. 